\title{
Simplified Quantitative Scoring on Shimada Risk \\ Stratification in Neuroblastoma
}

\author{
Abdolkarimi B ${ }^{1 *}$ and Salajegheh P $^{2}$ \\ ${ }^{1}$ Department of Pediatric Hematology Oncology, Lorestan University of Medical \\ Sciences, Iran \\ ${ }^{2}$ Fellowship of Pediatric Hematology Oncology, University of Medical Sciences, Iran
}

*Corresponding author: Babak Abdolkarimi, Department of Pediatric Hematology-

Oncology, Lorestan University of Medical Sciences, Shahidmadani Hospital, Tel: 989183605274; E-mail: b.abdolkarimi@yahoo.com

\section{Letter to Editor}

Neuroblastoma is the most common extra cranial solid tumor of infancy. It is an embryonal cancer of the sympathetic nervous system rising from pluripotent sympathetic cells [1].

Age, stage, and biological manifestations encountered in tumor cells are important prognostic factors and are used for risk stratification and treatment submission. The differences in outcome for patients with neuroblastoma are significant [2].

Patients with low-risk and intermediate-risk neuroblastoma have very good prognosis and outcome.
However, those with high-risk disease continue to have very poor outcomes inspite of intensive therapy. Unfortunately, almost $70-80 \%$ of patients older than 18 months present with diffuse disease, usually in the lymph nodes, liver, bone, and bone marrow. Less than half of these patients are cured, even with the use of high-dose therapy followed by autologous bone marrow transplant [3].

Various systems for determining patient risk neuroblastoma have arisen that one of them was expressed by Shimada.

\begin{tabular}{|c|c|c|c|c|c|}
\hline NSS Stage & Age & MYCN & Histopathology & DNA ploidy & Pisk group \\
\hline 1 & $0-21$ years & Any & Any & Any & Low \\
\hline $2 A / 2 B$ & $\begin{array}{l}<365 \text { days } \\
\geq 365 \text { days }-21 \text { years } \\
\geq 365 \text { days }-21 \text { years } \\
\geq 365 \text { days }-21 \text { years }\end{array}$ & $\begin{array}{l}\text { Any } \\
\text { Non-amp } \\
\text { Amp } \\
\text { Amp }\end{array}$ & $\begin{array}{l}\text { Any } \\
\text { Any } \\
\text { FH } \\
\text { UH }\end{array}$ & $\begin{array}{l}\text { Any } \\
- \\
- \\
-\end{array}$ & $\begin{array}{l}\text { Low } \\
\text { Low } \\
\text { Low } \\
\text { High }\end{array}$ \\
\hline 3 & $\begin{array}{l}<365 \text { days } \\
<365 \text { days } \\
\geq 365 \text { days }-21 \text { years } \\
\geq 365 \text { days }-21 \text { years } \\
\geq 365 \text { days }-21 \text { years }\end{array}$ & $\begin{array}{l}\text { Non-amp } \\
\text { Amp } \\
\text { Non-amp } \\
\text { Non-amp } \\
\text { Amp }\end{array}$ & $\begin{array}{l}\text { Any } \\
\text { Any } \\
\text { FH } \\
\text { UH } \\
\text { Any }\end{array}$ & $\begin{array}{l}\text { Avy } \\
\text { Any } \\
- \\
- \\
-\end{array}$ & $\begin{array}{l}\text { Intermediate } \\
\text { High } \\
\text { Intermediate } \\
\text { High } \\
\text { High }\end{array}$ \\
\hline 4 & $\begin{array}{l}<365 \text { days } \\
<365 \text { days } \\
\geq 365 \text { days - } 21 \text { years }\end{array}$ & $\begin{array}{l}\text { Non-amp } \\
\text { Amp } \\
\text { Any }\end{array}$ & $\begin{array}{l}\text { Any } \\
\text { Any } \\
\text { Any }\end{array}$ & $\begin{array}{l}\text { Any } \\
\text { Any } \\
-\end{array}$ & $\begin{array}{l}\text { Intermediate } \\
\text { High } \\
\text { High }\end{array}$ \\
\hline $4 \mathrm{~S}$ & $\begin{array}{l}<365 \text { days } \\
<365 \text { days } \\
<365 \text { days } \\
<365 \text { days }\end{array}$ & $\begin{array}{l}\text { Non-amp } \\
\text { Non-amp } \\
\text { Non-amp } \\
\text { Amp }\end{array}$ & $\begin{array}{l}\text { FH } \\
\text { Any } \\
\text { UH } \\
\text { Any }\end{array}$ & $\begin{array}{l}D>1 \\
D l=1 \\
\text { Any } \\
\text { Any }\end{array}$ & $\begin{array}{l}\text { Low } \\
\text { htermediate } \\
\text { intermediate } \\
\text { High }\end{array}$ \\
\hline
\end{tabular}




\section{Neurology \& Neurotherapy Open Access Journal}

We define a scoring system for simplifying this classification.

The scoring system is based on converted odds ratios derived by multivariable logistic regression analysis and includes 4 clinical variables due to classic Shimada clasification: N-mycamplification, stage, histology, DNA ploidy. Based on these variables, patients are assigned a clinical risk score, with a minimum score of 2 points. Subsequently, patients are classified into three categories. Patients with a clinical risk score of 0 or 1 are categorized as low risk, and intermediate risk and clinical risk score of 2 or more are categorized as high risk. The screening strategy based on this clinical scoring system is as follows: low risk patient have not treatment and often will be observed. Intermediate risk patients will be treated with the just chemotherapy. High risk patients will be also treated with the chemotherapy, and need autologous BMT.

Calibration and discrimination were assessed as measures of validity of the scoring system. Internal validity and External validity was assessed independently. Calibration was evaluated by a $\chi^{2}$ goodness of fit test, and discrimination was evaluated by calculating the area under the receiver operating characteristic (ROC) curve. The scoring system discriminated moderately (area under the curve $=0.64$ (95\% CI 0.56-0.72)). Calibration was limited $(\operatorname{chi}(2)=8.89, \mathrm{p}=0.06)$.

Each category includes minimum 2 parameters in classical Shimada risk stratification. Categories were defined within each resultant score, and odds ratios were estimated with their respective 95\% confidence interval for each category when compared to the reference category using logistic regression models. ROC curves were then generated and areas under the curve (cstatistics) were computed. Analyses were performed using statistical software R, v. 2.15.2. [5-7]

Total Score $0=$ low risk $(\mathrm{p}<0.1)$

Total Score $-1=$ intermediate risk $(\mathrm{p}<00.1)$

Total Score $-2=$ high risk $(\mathrm{p}<000.1)$

Scoring value for Stage $4 S=-1$,

Scoring value for Stage I, II, $=0$

Scoring value for Stage III $=-1$

Scoring value for Stage IV $=-2$

Scoring value for age $=0$

Scoring value for $\mathrm{N}$-mycamplification $(+)=-1$

Scoring value for $\mathrm{N}-$ mycNON amplification $(-)=+1$

Scoring value for unfavorable histology $=-1$

Scoring value for favorable histology $=+1$
Scoring value for hyperdiploidi $(\mathrm{DI}>1)=+1$

Scoring value for hypodiploidi $(\mathrm{DI}<1)=-1$

Scoring value for age is separated from other risk factors and our classification scoring is independent to patient,s age.

With this scoring simplification oncologists don't need refer to Shimada table or memorize its content.

For example 4S with NMYC amplification has risk sore $=(-$ $1)+(-1)=-2$ therefore it is a high risk patient.

Or patient with stage IV and non NMYC amplification has risk

score $=(-1)+(-1)=-2$ therefore it is a high risk patient.

In conclusion, despite different complex stratification systems, the individual tumor behavior is at times not recognizable on initial presentation. Therefore, all current trials still fail to determine the best initial strategy for a substantial number of patients, resulting in both overand under-treatment of a yet unknown number of cases. This new method can facilitate application of Shimada classificationtable for pediatric oncologists and permit adding other factors for risk stratification.

Keywords: Schimad; Neuroblastoma; Scoring

\section{References}

1. Mora J, Gerald WL (2004) Expert review of molecular diagnostics. Origin of neuroblastic tumors: clues for future therapeutics 4(3): 293-302.

2. Gupta H, Conrad J, Khoury JD, McGregor LM, Krasin MJ, et al. (2007) Significance of pleural effusion in neuroblastoma. Pediatric blood cancer 49(7): 906908.

3. Look AT, Hayes FA, Shuster JJ, Douglass EC, Castleberry RP, et al. (1991) Clinical relevance of tumor cell ploidy and $\mathrm{N}$-myc gene amplification in childhood neuroblastoma: a Pediatric Oncology Group study. J Clin Oncol 9(4): 581-591.

4. Spitz R, Hero B, Ernestus K, Berthold F (2003) FISH analyses for alterations in chromosomes 1, 2, 3, and 11 define high-risk groups in neuroblastoma. Med Pediatr Oncol 41(1): 30-35.

5. Formicola D, Petrosino G Lasorsa V, Pignataro P, Cimmino F, et al. (2016) Vito Alessandro Lasorsa. An 18 gene expression-based score classifier predicts the clinical outcome in stage 4 neuroblastoma. J Transl Med 14(1): 142. 


\section{Neurology \& Neurotherapy Open Access Journal}

6. Wood G, Barayan G, Sanchez DC, Inoue GN, Buchalla CA, et al. (2013) Validation of the pediatric surgical risk assessment scoring system. J Pediatr Surg 48(10): 2017-2021.
7. Caliskan E, Kayikcioglu F, Ozturk N, Koc S, Haberal A (2004) A population-based risk factor scoring will decrease unnecessary testing for the diagnosis of gestational diabetes mellitus. Acta Obstet Gynecol Scand 83(6): 524-530. 